\title{
The Impact of Financial Sector Sustainability Guidelines and Regulations on the Financial Stability of South American Banks
}

\author{
Pedro Ildemaro Alguindigue Ruiz, Olaf Weber* \\ University of Waterloo
}

\section{ARTICLE INFO}

\section{Article history:}

Received 16 March 2021

Revised 17 May 2021

Accepted 02 June 2021

Published 07 June 2021

\section{Keywords:}

Sustainability

Regulation

Supervision

Financial stability

South-America

\section{ABSTRACT}

Sustainability risks represent a significant concern for the banking industry. Consequently, financial regulators created financial sector sustainability guidelines and regulations. However, the effect of these policies on banks' financial stability is unclear. Hence, this study analyzes 149 banks in 17 countries in Latin America to explore the impact of financial sector sustainability guidelines and regulations on the banking industry. We use the Z-Score to measure the financial stability of banks in countries with and without financial sector sustainability guidelines and regulations. Based on panel regression, our results suggest significant differences between banks in countries with and without financial sector sustainability guidelines and regulations. We conclude that sustainable finance regulations promote financial stability as well as sustainable banking practices.

\section{Introduction}

Financial stability is a necessary condition that economies should maintain to pursue economic development (Schinasi, 2004). A stable financial sector helps an economy grow, absorb adverse economic shocks, and reduce economic and social impacts (Allen, 2011; Jiang et al., 2019). Recently, however, financial regulators and academic studies have emphasized the effects of sustainability-related concerns, such as climate change, on financial stability (Battiston et al., 2017; Carney, 2015; Dafermos et al., 2018). Consequently, managing climate-related impacts on financial stability through financial sector sustainability regulations and guidelines (FSSRG) might positively influence financial stability.

Research on the impact of FSSRGs on firms' financial performance and financial stability is relatively recent. Current academic literature addresses China's Green Credit Policy (Cui et al., 2018; Zhang et al., 2011). Also, studies

* Corresponding author.

E-Mail address: oweber@uwaterloo.ca

ORCID: 0000-0001-6602-0459 
on Bangladesh have been conducted after the country introduced the Environmental Risk Management (ERM) guideline (Weber \& Chowdury, 2020). Furthermore, other studies address the impact of voluntary codes of conduct in the financial sector, such as the Equator Principles or the UNEP Financial Initiative. For instance, Scholtens and Dam (2007) did not find any differences in the financial performance of Equator Principles banks and other banks.

Some of the benefits of FSSRG might be risk reduction (Weber, 2017) and higher performance of the financial industry (Dam \& Scholtens, 2015; Monasterolo \& Raberto, 2018). Consequently, an increasing number of financial regulators have introduced FSSRG (Zadek \& Robins, 2018), addressing financial industry sustainability impacts and financial stability (Weber \& Feltmate, 2016). The introduction has led towards benefits in terms of social, economic, and environmental impacts (Weber, 2017). Whether the assumption that FSSRG has a positive effect on the financial sector's stability is correct is still an open question that this study addresses.

Research that covers the impact of FSSRG in the Latin American region is scarce. Between 2008 and 2018, six countries in Latin America, Brazil, Colombia, Ecuador, Mexico, Panama, and Peru, incorporated FSSRG in their financial systems. These policies helped banks adopt sustainable practices in their organizational culture and business practices (Oyegunle \& Weber, 2015). The question remains, however, how FSSRG influence the financial stability in the region.

Consequently, this research paper aims to understand the macroprudential implications of FSSRGs. Based on financial stability and systemic risk theory (Acharya, 2009; Benoit et al., 2017). The research question is whether FSSRG positively influences the financial stability of countries in Latin America.

The study analyzed FSSRG in Latin America, including data from 149 banks. We used a dynamic panel data analysis to compare the stability of banks operating in countries with and without FSSRGs and guidelines between 2008 and 2018.

We found that FSSRGs have a positive and significant impact on the financial stability of banks in Latin America. We conclude that banks that operate in countries with FSSRG have a higher level of corporate sustainability practices, reduce financial risk from activities with the potential to detriment the environment and society.

The study results build on existing research regarding the importance of climate mitigation policies in the banking sector (Battiston et al., 2017) and financial stability through FSSRG (Zadek \& Robins, 2015). It provides several contributions to the academic literature. First, the study provides a better understanding of the financial implications of FSSRG. Second, these results contribute to the knowledge about the impact of FSSRG in Latin America. Third, this study broadens the theory on financial stability and systemic risk (Acharya, 2009; Benoit et al., 2017) by adding FSSRGs as an additional factor, which can develop into an empirical foundation to build a theoretical framework connecting financial stability and sustainability, following previous theories on financial stability.

The remainder of this paper is structured as follows: Section 2 consists of a review of the literature on sustainable finance, financial stability, financial regulations, and their linkage. The methodology and methods used to analyze the data will be explained in Section 3, followed by the results section in Section 4. Finally, Section 5 presents a discussion of those results, and Section 6 describes the study's concluding remarks. 


\section{Background}

The following sections describe the academic literature on financial stability, sustainable finance, including its effects on banking risk and financial stability, and sustainable and traditional regulations in the financial sector as macroprudential policies. A rationale for FSSRGs as an evident and necessary macroprudential policy is presented. We explain the increasing challenges of sustainability-related financial risks and the potential for sustainable finance to diminish this systemic risk (Hayne et al.). Additionally, we introduce the main theories that explain systemic risk sources and the primary regulations and guidelines to avoid financial instability. Finally, we present the central hypothesis of this research paper based on the identified literature gap.

\section{Sustainability and Financial Stability}

Literature linking sustainability and financial stability is relatively new (Battiston et al., 2017; Cui et al., 2018). Failure to address sustainability risks, such as climate change, can materialize into external shocks and systemic risk (Campiglio et al., 2018). Therefore, markets' timing and ability to respond to external environmental and societal shocks are crucial to preserving financial stability (Battiston et al., 2017). Hence, FSSRG might help to decrease the exposure to sustainability risks.

Other studies have shown the detrimental implications on the financial system that arise from climate risk (Dietz et al., 2003; Klomp, 2014; Scott et al., 2017; Skidmore, 2001) as well as the systemic risk that it carries (Campiglio et al., 2018; Dietz et al., 2016; Rozenberg et al., 2013). The size and scope of climate-related catastrophes, the development level of the financial markets, and the acerbity of financial regulations play a crucial role when determining the impacts of a natural disaster on a country's financial system (Klomp, 2014). Climate change and social-political responses also negatively affect the financial sector through transitional and physical risks (Scott et al., 2017). Such risks include a substantial threat to the liquidity (Klomp, 2014), asset value (Dietz et al., 2016), the rate of non-performing loans, the portfolio allocation and economic activity of banks, and, consequentially, the financial system and systemic stability. Households are potentially affected by the exposure of pension funds and pension schemes to climate risk (Monasterolo et al., 2017).

Additionally, there is a positive correlation between household savings rates and damages caused by natural disasters (Skidmore, 2001). Because of an increase in their frequency caused by climate change, natural disasters decrease financial stability. Furthermore, the efficiency of economic policies that do not consider sustainability risks is small if climate-related damages influence the economy (Dafermos et al., 2018). However, considering sustainability risks through socially responsible investment might help managing these risks (Nofsinger \& Varma, 2014).

With the increase of climate-related risks, carbon externalities should be considered to assess and manage financial stability (Rozenberg et al., 2013). Thus, societies need to avoid excessive economic losses and keep their financial system stable (Campiglio et al., 2018) while shifting to a low-carbon economy or face the irreversible economic consequences of climate change and natural disasters (Dietz et al., 2016). Hence, financial regulators and supervisors 
can create incentives for the financial sector to reduce their portfolio's climate exposure by reducing their exposure to high emitting industries (Carè, 2017; Monasterolo et al., 2017).

\subsection{Sustainable Finance}

Sustainable practices in financial institutions address risks and opportunities arising from (un)sustainable development for the financial industry as well as positive and negative impacts of the financial sector on sustainable development (Dam \& Scholtens, 2015; Weber \& Feltmate, 2016). Sustainable finance practices to manage risks for the industry are sustainable credit risk management and reducing the climate exposure of lending portfolios (Weber et al., 2010). Sustainability-related opportunities might be socially responsible investment products (Scholtens et al., 2008). Positive sustainability impacts of the financial industry might occur through issuing green bonds (Saravade \& Weber, 2020) and impact investing (Jackson, 2013). Negative impacts might arise by financing unsustainable projects, such as coal power plants (Sarro, 2012).

Simulations show that green public policies can promote green growth by influencing firms' expectations and the credit market. Green sovereign bonds represent a short-term win-win solution, while green fiscal measures have higher immediate distributive effects that induce negative feedback on the economy (Monasterolo \& Raberto, 2018). Therefore, financial institutions and central banks must contemplate and account for environmental risks. Research suggests that modern finance is transitioning towards sustainability due to external shocks, such as climate change, water insecurity, low carbon markets, and new financial products and incentives (Weber, 2005). Furthermore, financial institutions' disclosure of sustainability measures and practices is critical (Pellegrino \& Lodhia, 2012). However, it is essential to increase transparency and standardize indicators and reporting (ElAlfy et al., 2020). To support these goals, institutional activities that support guidelines and regulations might help.

\section{Banking Regulations and Financial Stability}

Policymakers mainly use regulations in the financial sector to guarantee the industry's financial stability through the adjusted financial capital provision and financial risk supervision (Acharya, 2009). Studies recommend creating incentives for the banking sector, such as prudential regulations and supervision, to develop institutional bank stability (Anginer \& Demirguc-Kunt, 2014). Prudential regulations and supervision have been resulting in higher quality loans and lower moral hazard (Shehzad \& De Haan, 2015) as well as limiting the engagement of banks in non-interest income activities (Bermpei et al., 2018) and systemic risk (Acharya, 2009). However, other studies have shown concern towards financial institutions being too big to fail. The 2007-2009 subprime crisis demonstrated the risk these financial institutions represent. Their expectations of being partially restored by monetary authorities in case of a crisis (Tabak et al., 2013) compromises the stability of the global financial system.

Regulations that incorporate capital requirements and supervisory power reduce non-performing loans and credit risk (Agoraki et al., 2011). Financial institutions, however, tend to be cautious of possible financial implications and financial uncertainties from financial regulations (Dam \& Scholtens, 2015). These findings and the change of behaviour in the industry have increased financial regulations (Barth et al., 2004). 
Furthermore, regulatory effectiveness correlates with a country's institutional quality. Regulations in countries with weak institutions are associated with higher corruption in the lending process with no similar beneficial effects on stability (Barth et al., 2004). Also, regulations alone have no control over financial crises; policymakers must consider other mechanisms and preventive measures at the institutional level (Allen \& Gu, 2018). Hence, political stability is essential to increase the benefits of financial industry regulations (Bermpei et al., 2018).

Until recently, financial supervision and regulation did not include any non-financial sustainability considerations. This changed, however, with the rise of climate-related financial impacts on the banking sector (Campiglio et al., 2018) and with the introduction of green finance and sustainable finance (Weber \& Feltmate, 2016).

\section{Financial Stability and FSSRGs}

The amount of existing literature that evaluates climate change and other sustainability issues' repercussions on financial stability is scarce since most of it is based on direct effects on banks and other financial institutions (Cui et al., 2018; Dam \& Scholtens, 2015). It suggested, however, that it is imperative to adopt the necessary measures to protect the financial stability from influences of climate change and other environmental and societal risks the financial industry is exposed to (Battiston et al., 2017).

Regulatory standards also play an essential part in the application of sustainable practices in financial markets. Nowadays, financial markets are vigilant of the uncertain financial implications that result from environmental regulatory interventions as the demands for stricter environmental regulations increase (Bauer \& Hann, 2010). Central Banks and governments implement FSSRGs, hoping that these policies increase financial stability, foster green economic development, and enhance the financial and environmental performance of the financial industry. Regulations such as green credit policies can improve the financial industry's corporate sustainability and create a more stable and profitable financial sector (Weber, 2017). For instance, several countries, such as China, Brazil, and Bangladesh, have adopted FSSSRG to reduce the carbon exposure of the financial industry (Zadek \& Robins, 2015). Some academic studies have already analyzed the effect of FSSRG.

Studies on the Environmental Risk Management (ERM) Guidelines in Bangladesh suggest that the integration of sustainability criteria in credit risk assessment helps lenders to predict credit risks better. Furthermore, banks that perform better with regard to corporate sustainability also improve their financial performance (Weber \& Chowdury, 2020).

China's Green Credit Policy in China addresses environmental and financial performance, creating institutional pressure on the Chinese Financial system (Cui et al., 2018). The starting year of the Green Credit Policy was 2007. The State Environmental Protection Administration (SEPA), the People's Bank of China (PBOC), and the China Banking Regulatory Commission (CBRC) published a joint policy on implementing FSSRG and managing credit risks (Aizawa \& Chaofei, 2010; China Banking Regulatory Commission, 2012). Consequently, banks had to allocate more investment towards green industries as well as constrain investments in polluting industries. The regulation is mandatory for all Chinese banks regardless of ownership structure and covers government-owned banks, joint-stock banks, and credit unions (China Banking Regulatory Commission, 2012). 
Chinese banks introduced environmental policies, strategies, and assessment systems to evaluate credit clients (Chan-Fishel, 2007). Subsequently, additional guidelines were put in place to support the development of the Green Credit Policy. In 2009, the China Banking Association issued guidelines on corporate social responsibility, asking banks to take on environmental responsibility in supporting national industrial policies and environmental policies. The CBRC issued a formal document entitled the Green Credit Guideline in 2012. The guideline encouraged "banking institutions to, by focusing on green credit, actively adjust credit structures, effectively fend off environmental and social risks, better serve the real economy, and boost the transformation of an economic growth mode and adjustment of economic structures" (China Banking Regulatory Commission, 2012, p. 1).

By the end of 2015, China's financial institutions provided a total of $\$ 1.24$ trillion in green credit. Furthermore, the supervisor announced that the NPS of green loans was lower than the average of all loans (China Banking Regulatory Commission, 2016). Hence, it seems that the policy achieved its goal to increase environmental performance and financial stability (Chih et al., 2010).

Overall, the research found that Banks in countries with FSSRG engage in more corporate social responsibility (CSR) activities and self-regulation (Chih et al., 2010). The relevant politics of green finance can ease the financing bottleneck that the government faces to some degree, combined with reform and innovative financial tools. The policies include two aspects: first, the reform and innovation of existing financial instruments, an exploration of the type of fiscal policy and the feasible way to raise money for green finance development; second, the reform of existing fiscal revenue management and distribution policy, namely the efficiency and direction in the use of monetary funds (Wang \& Zhi, 2016).

During the last 20 years, Latin America has seen notable socio-economic improvement. During this period, several countries in the region exhibited a degree of macroeconomic stability, probably never seen since their independence. Indeed, 16 Latin American countries have managed to sustain one-digit inflation rates with stable growth rates in the established study period (2008-2018). According to World Bank Data (https://data.worldbank.org/indicator/NY.GDP.MKTP.CD), in 2019, the average GDP of the South American countries in our sample has been $\$ 314$ billion, with Nicaragua as the country with the lowest GDP (412.5 billion) and Brazil with the highest GDP ( $\$ 1840$ billion). The compound annual growth rate between 2008 and 2018 has been $2.3 \%$. These countries had 17.01 commercial bank branches per 100,000 adults compared to a global average of 16.53. In 2018 the average Bank Capital to Asset Ratio for the countries in the same was11.2 percent compared to the worldwide average of 10.7 percent according to Worl Bank data (https://data.worldbank.org/indicator/FB.BNK.CAPA.ZS?view=chart). Also, six Latin American countries started building FSSRG (Oyegunle \& Weber, 2015), including environmental and social risk management practices, project finance, and other aspects regarding sustainability in the financial sector (see Table 1).

The introduction of FSSRGs in Latin America began in 1995 with Brazil's Protocolo Verde (The Green Protocol), which introduced socio-environmental and sustainable intentions from several financial institutions. Brazil's Green Protocol was revised later in 2008 and served as inspiration for more countries in the region, such as Colombia (Protocolo Verde in 2012), Peru (Regulation for Social and Environmental Risk Management in 2015), Ecuador (Sustainable banking Protocol in 2016), Mexico (Sustainable banking Protocol in 2016), and Panama (Panama's 
Sustainable banking Protocol in 2018). Today, these countries have introduced more sustainable and socioenvironmental initiatives to motivate the banking sector's sustainable practices.

Of the countries in the sample, 12 have not introduced FSSRG as of 2018. These countries are Argentina, Bolivia, Chile, Costa Rica, Dominican Republic, El Salvador, Guatemala, Honduras, Nicaragua, Puerto Rico, Uruguay, and Venezuela. Though some South American countries have introduced FSSRGs, there is no research on the effect of these policies on financial stability. This paper addresses this gap.

Table 1. List of FSSRGs

\begin{tabular}{|c|c|c|c|}
\hline Country & Key Policies & Policy Aim & $\begin{array}{l}\text { Date } \\
\text { Established }\end{array}$ \\
\hline \multirow[t]{7}{*}{ Brazil } & Protocolo Verde & Sustainable Finance Practices & 1995 \\
\hline & Regulation $\mathrm{N}^{\circ} 3,545$ & Protection of the Amazon Biome & 2008 \\
\hline & Regulation $\mathrm{N}^{\circ} 3,813$ & Sugarcane investment & 2009 \\
\hline & Regulation $\mathrm{N}^{\circ} 3,876$ & Slave labour & 2010 \\
\hline & Regulation $\mathrm{N}^{\circ} 3,547$ & $\begin{array}{l}\text { Good practices that mitigate environmental and } \\
\text { social risks }\end{array}$ & 2011 \\
\hline & Regulation $\mathrm{N}^{\circ} 4,327$ & $\begin{array}{l}\text { Social and Environmental Responsibility for } \\
\text { financial institutions }\end{array}$ & 2014 \\
\hline & Regulation $\mathrm{N}^{\circ} 4,557$ & $\begin{array}{l}\text { Social and Environmental Responsibility for } \\
\text { financial institutions }\end{array}$ & 2017 \\
\hline Colombia & Protocolo Verde & Green Finance & 2012 \\
\hline Ecuador & Protocolo de Banca Sustentable. & Green Finance & 2016 \\
\hline \multirow[t]{2}{*}{ Mexico } & $\begin{array}{l}\text { Protocolo de Sustentabilidad de la } \\
\text { Banca }\end{array}$ & Sustainable Banking Requirements & 2016 \\
\hline & Green Bonds Principles & Green Finance & 2018 \\
\hline Panama & $\begin{array}{l}\text { Protocolo de Finanzas } \\
\text { Sustentables de Panamá }\end{array}$ & Green Finance & 2018 \\
\hline \multirow[t]{3}{*}{ Peru } & Resolution $\mathrm{N}^{\circ} 1928-2015$ & $\begin{array}{l}\text { Regulation for Social and Environmental Risk } \\
\text { Management }\end{array}$ & 2015 \\
\hline & Document SBS Nº1-2015 & $\begin{array}{l}\text { Enhanced due diligence in the regulation of } \\
\text { socioenvironmental risk management for } \\
\text { financial firms }\end{array}$ & 2015 \\
\hline & $\begin{array}{l}\text { Guía de Bonos Verdes para el } \\
\text { Perú. }\end{array}$ & Green Bonds Guidelines & 2018 \\
\hline
\end{tabular}

\subsection{Theoretical Framework}

Our theoretical framework uses the theory of systemic risk. According to this theory, the design of prudential bank regulations influences systemic risk. Hence, a regulatory body to create policies that avoid systemic risk is essential. The theory, introduced by Acharya (2009), "incorporates the likelihood of default by banks on deposits, financial externalities from the failure of one bank on other banks, regulatory incentives, and the interaction of these features" (pp. 228). The theory includes a normative and a systemic feature. The positive component of the theory defines systemic risks and their equilibrium. Meanwhile, the normative component designs regulations to alleviate inefficient systemic risk.

The theory, within its positive feature, models the concept of systemic risk-shifting, the choice of correlation across assets between different banks given the existence of limited liability and a negative externality of default by 
banks (Acharya, 2009; Jensen \& Meckling, 1976; Stiglitz \& Weiss, 1988). In other words, banks decide to invest in the same assets to reduce the effects of negative externalities (Benoit et al., 2017). The firms' lack of liability nullifies the limits of correlation that banks would compromise as they prefer to survive with the crisis, as they benefit from this correlation thanks to bailouts. Furthermore, the theory explains specific regulations that should be avoided (Farhi \& Tirole, 2012). It describes a regulatory framework that includes a bank closure policy and capital requirements to reduce the chances of a massive bank bailout scenario (Acharya, 2009), liquidity requirement, or, equivalently, of a cap on short-term debt (Farhi \& Tirole, 2012).

Above, we presented studies suggesting that climate change has a systemic impact on the banking industry (Campiglio et al., 2018; Dietz et al., 2016; Dietz et al., 2003; Klomp, 2014; Rozenberg et al., 2013; Scott et al., 2017; Skidmore, 2001). Hence, in line with Acharya (2009), climate change might increase the probability of default by banks, and consequently, creates a systemic risk if the effect of climate change is the same for the major banks in a country. Therefore, regulating sustainability-related banking activities by integrating FSSRG into the regulatory framework will increase the quality of risk supervision and financial stability if the FSSRG addresses material sustainability risks for the financial sector. Hence, our hypothesis is that countries that introduced FSSRG have a higher financial stability than countries without FSSRG.

Based on the systemic risk theory, we use the Z-Score to assess the financial stability of the banking industry. The Z-Score focuses on assets and equity, and consequently, is an indicator for financial stability based on available capital (Anginer \& Demirguc-Kunt, 2014). We describe the Z-Score more in detail in the Methods and Data section. The existence of FSSRG is operationalized through a categorical yes - no variable.

\section{Research Objective and Questions}

Several studies have shown the effects of regulations on financial stability (Acharya, 2009; Farhi \& Tirole, 2012), of sustainability risks on portfolio risks (Battiston et al., 2016; Dorfleitner \& Utz, 2012; Monasterolo \& Raberto, 2018), and have shown the effect of FSSRG on credit risk (Cui et al., 2018). Though these three types of studies exist, there is a gap in the research about how they are linked. Studies that analyze the effect of FSSRG on financial stability do not exist yet. Therefore, this study aims to understand the connection between FSSRG and the financial stability of the financial sector to explore the potential of sustainability-related financial sector regulations and guidelines. Consequently, our research question analyses whether having introduced FSSRG has a positive effect on the financial stability of the financial sector measured by the Z-Score. We hypothesize that FSSRG increases the financial stability of the banking sector. The methods and data used to respond to the research question are presented in the following section. Using standard methods and variables used to assess financial stability by financial regulators will contribute to the knowledge about FSSRG and financial stability and will provide insights for policymaking.

\section{Methods and Data}

The following section explains the data and the methods used in this study. To evaluate the relationship between financial stability and FSSRGs, we applied a panel regression analysis. The sample data for this study consists of an 
unbalanced panel data of 149 banks from a comprehensive international data set from 17 countries: Argentina, Bolivia, Brazil, Chile, Colombia, Costa Rica, Dominican Republic, Ecuador, Guatemala, Honduras, Mexico, Panama, Paraguay, Peru, Puerto Rico, Uruguay, and Venezuela between 2008 and 2018. There were three main criteria to choose the countries for the samples. First, the countries must be in Latin America and the Caribbean; Second, the countries must belong within the highest 20 countries regarding GDP per capita in 2018; third, these countries banks' data must be accessible financial data. Therefore, this study uses 1240 cross-sectional segments (see Table 2).

Table 2. Countries and number of banks in the sample

\begin{tabular}{|c|c|c|}
\hline Row Labels & Number of Banks & Number of Observations \\
\hline Argentina & 12 & 102 \\
\hline Bolivia & 10 & 68 \\
\hline Brazil & 10 & 100 \\
\hline Chile & 10 & 101 \\
\hline Colombia & 10 & 85 \\
\hline Costa Rica & 10 & 102 \\
\hline Dominican Republic & 10 & 59 \\
\hline Ecuador & 4 & 32 \\
\hline Guatemala & 9 & 37 \\
\hline Honduras & 10 & 61 \\
\hline Mexico & 9 & 99 \\
\hline Panama & 10 & 102 \\
\hline Paraguay & 10 & 82 \\
\hline Peru & 10 & 109 \\
\hline Puerto Rico & 2 & 19 \\
\hline Uruguay & 7 & 34 \\
\hline Venezuela & 6 & 48 \\
\hline Total & 149 & 1240 \\
\hline
\end{tabular}

The bank-level data collection consisted of a mixture of manual compilation from the banks' annual reports and consolidated financial statements available on the banks' website, mainly the Balance Sheet and Income Statements between 2008 and 2018. Then, we extracted in a spreadsheet the total assets, total liabilities, total equity, loan loss provision, and net income for each bank. The bank-level variables gathered were total assets, total liabilities, total loans, and total income after taxes. Additionally, the data analysis process includes financial and macroeconomic variables as control variables. These indicators are the Gross Domestic Product (GDP) and Inflation (using the GDP deflator), which were obtained through the International Monetary Fund (IMF) database (https://data.imf.org/?sk=85b51b5a-b74f-473a-be16-49f1786949b3). 
Additional calculations, such as the Z-Scores, the return of assets (ROA), the equity-to-assets ratio, and the loan loss provision to total loan ratio, have been conducted. We used the latter because Bermpei et al. (2018) found that the loan loss provision to total loan ratio significantly affects bank stability.

To assess the level of financial stability for each bank each year, we use the Z-Score. This indicator is prevalent in empirical studies to determine the level of a bank's financial stability (Beck et al., 2007; Bermpei et al., 2018; Boyd \& Runkle, 1993; Čihák \& Hesse, 2010; Demirguc-Kunt et al., 2006; Laeven \& Levine, 2009). It represents the value that measures the solvency risk of a bank by relating its capital level to the variability in its returns, or "the number of standard deviations that a bank's return on assets has to fall for the bank to become insolvent (Anginer \& Demirguc-Kunt, 2014, p. 628). Hence, the Z-Score is defined as:

$$
Z_{i t}=\frac{R O A_{i t}+E A_{i t}}{\sigma R O A_{i t}}
$$

Where, $Z_{i t}$ stands for the Z-Score of the bank $i$ in the year $t, R O A_{i t}$ stands for the return of assets of the bank $i$ in the year $t$; $\mathrm{E} / \mathrm{A}_{\mathrm{it}}$ represents $\mathrm{EA}_{\mathrm{it}}$ the equity-to-assets ratio of the bank $i$ in year $t$, and $\sigma R O A_{i t}$ in the year $t$.

$R O A_{i t}$ is calculated by dividing the net income of a bank by its total assets after taxes. Furthermore, $E A_{i t}$ consists of the ratio obtained when dividing a bank's total shareholder equity by its total assets. Finally, to calculate $\sigma R O A_{i t}$ while avoiding disturbances or bias given by the timeframe used, this study will use three-year rolling time windows following the methodology by Bermpei et al. (2018).

This study uses a categorical dichotomic variable to compare banks that operate in countries with and without FSSRG. The values for these variables are either 1 or 0 , depending on the existence of FSSRG. We gathered the data regarding the existence of FSSRGs in each country by reviewing the 2018 Sustainable Banking Network (SBN) Global Progress Report (World Bank., 2018). Additionally, we searched for potentially exisiting FSSRGs of the countries used in the sample that did not appear in the SBN's report, such as Argentina, Bolivia,Bolivias and Chile, Costa Rica, Dominican Republic, El Salvador, Guatemala, Honduras, Nicaragua, Puerto Rico, Uruguay, and Venezuela. However, none of the countries mentioned above had incorporated any FSSRG by 2018.

Further, we used several variables to control exogenous effects that could affect the dependent variable. All the control variables are continuous variables that represent ratios of either financial or macroeconomic data. The banklevel control variables used in this research are the equity to asset ratio, total asset growth, capital to asset ratio, Return on Assets (ROA), loan loss provision to loan loss ratio. The equity to asset ratio is measured by the ratio of the total equity to total assets. It represents a bank's capitalization, which is expected to have a neutralizing effect on the bank risk-capital regulation nexus (Acharya et al., 2017; Delis et al., 2012). The total asset growth is used to control for bank growth and its connection to higher risk (Bermpei et al., 2018; Demirguc-Kunt \& Huizinga, 2009), measured by subtracting a bank's total assets from the value of the previous year. Loan loss provision to total loss ratio is used as a proxy of a bank's loans, calculated by the ratio of a bank's loan-loss provision to the total loans.

The macroeconomic control variables are the growth of the gross domestic product (GDP growth) and the inflation rate. GDP growth will cover the effect of economic conditions, calculated by subtracting the gross domestic product of a country in a specific year with the value of that variable the previous year and finally divided by the GDP of the 
previous year. The inflation rate embodies a proxy for monetary conditions, using the GDP deflator. The data for these indicators were collected from the database of the IMF (IMF, 2020).

This research paper uses a fixed-effect panel data analysis (Petersen, 2009) to study the influence of FSSRG on the countries' systemic financial stability in the region. We used a Hausman Test to tests for the use of fixed vs. random effects (Hausman, 1978).

\section{Results}

The following section presents the results of the statistical analyses. The first subsection describes the descriptive statistics of the variables used in the study. Second, this section presents the result of the panel regression.

\section{Descriptive Statistics}

Table 3 presents the descriptive statistics for all the indicators used in this paper. The data analyzed consists of 1639 observations with one dependent variable Z-Score, two independent variables, FSSRG and total asset growth, and five instrumental variables, $R O A, A / E, L L P / T L, d G D P$, and the inflation rate, in a timeframe of 11 years. The individual Z-Score values of the banks can be found in the Excel File ZScore Values in the supplement.

Table 3. Descriptive Statistics

\begin{tabular}{|c|c|c|c|c|c|}
\hline & Mean & Median & Minimum & Maximum & Std. Dev. \\
\hline Total Asset Growth & 0.0156 & 0.0101 & -0.4398 & 0.8264 & 0.0526 \\
\hline $\mathrm{A} / \mathrm{E}$ & 0.1072 & 0.0959 & -0.9444 & 0.9993 & 0.0863 \\
\hline ROA & 0.0148 & 0.013 & -0.0301 & 0.1224 & 0.0112 \\
\hline LLP/TL & 0.0414 & 0.0273 & -0.1199 & 1.5034 & 0.0896 \\
\hline dGDP & 0.07 & 0.0678 & -0.2662 & 0.3764 & 0.1022 \\
\hline Inflation & 6.683 & 4.676 & -4.6206 & 41.119 & 7.4243 \\
\hline Z-Score & 72.72 & 40.743 & 0.298 & 1682.5 & 115.94 \\
\hline
\end{tabular}

First, the dependent variable $Z$-Score ${ }_{i, t}$ has a mean of 72.72 and a standard deviation of 115.94 , reaching its lowest value was 0.2.8 and its highest at 1682.5. The Z-Score has 399 missing values, the highest number of missing values for any variable in the dataset.

Furthermore, the independent variable, FSSRG, has 1,639 observations because we collected the data for all the banks in the sample for ten years. For this sample, 1,291 are 0s or, in other words, come from countries that do not have FSSRGs ( $78.77 \%$ of the total sample). Regarding the 1s or the data points from countries that enforce these policies, there are 348 observations ( $21.77 \%$ of the total sample). There are no missing values for this variable. Lastly, the independent variable $\mathrm{g}(\mathrm{i}, \mathrm{t})$ has a mean of 3.7342 and a standard deviation of 1.1956 , with a minimum value of 1.1289 and a maximum value of 10.7520 . 
Table 4 presents the correlation between the variables. The correlations are relatively low, indicating the independence between the variables and a low risk of autocorrelation (Anderson, 1954).

Table 4. Correlation coefficients

\begin{tabular}{llllllll}
\hline & Total Asset Growth & E/A & ROA & LLP_TLR & dGDP & Inflation & Z-Score \\
\hline Total Asset Growth & & -0.0353 & -0.0148 & -0.0194 & $0.2423^{* *}$ & -0.0508 & -0.0448 \\
A/E & -0.0353 & & $0.1948^{* *}$ & -0.0462 & -0.0107 & 0.0332 & $0.2424 * *$ \\
ROA & -0.0148 & $0.1948^{* *}$ & & $0.0742^{* *}$ & 0.0254 & $0.2994^{* *}$ & -0.0562 \\
LLP/TL & -0.0194 & -0.0462 & $0.0742^{* *}$ & & -0.0157 & $0.0854^{* *}$ & -0.0209 \\
dGDP & $0.2423 * *$ & -0.0107 & 0.0254 & -0.0157 & & 0.0365 & -0.0046 \\
Inflation & -0.0508 & 0.0332 & $0.2994^{* *}$ & $0.0854^{* *}$ & 0.0365 & $-0.1007 * *$ \\
Z-Score & -0.0448 & $0.2424 * *$ & -0.0562 & -0.0209 & -0.0046 & $-0.1007 * *$ & \\
\hline
\end{tabular}

$*, * *$ indicate significance at the $95 \%$ and $99 \%$ level, respectively.

\section{Analysis of the Impact of FSSRGs}

The difference between the Z-Score of regulated vs. non-regulated countries is presented in Figure 1. We converted the Z-Score values to $\ln (\mathrm{Z})$ to provide a better illustration of the data. The Z-Score of countries without FSSRG is significantly smaller than the Z-Score for countries with FSSRG (t-test, $\mathrm{p}<.001$ )

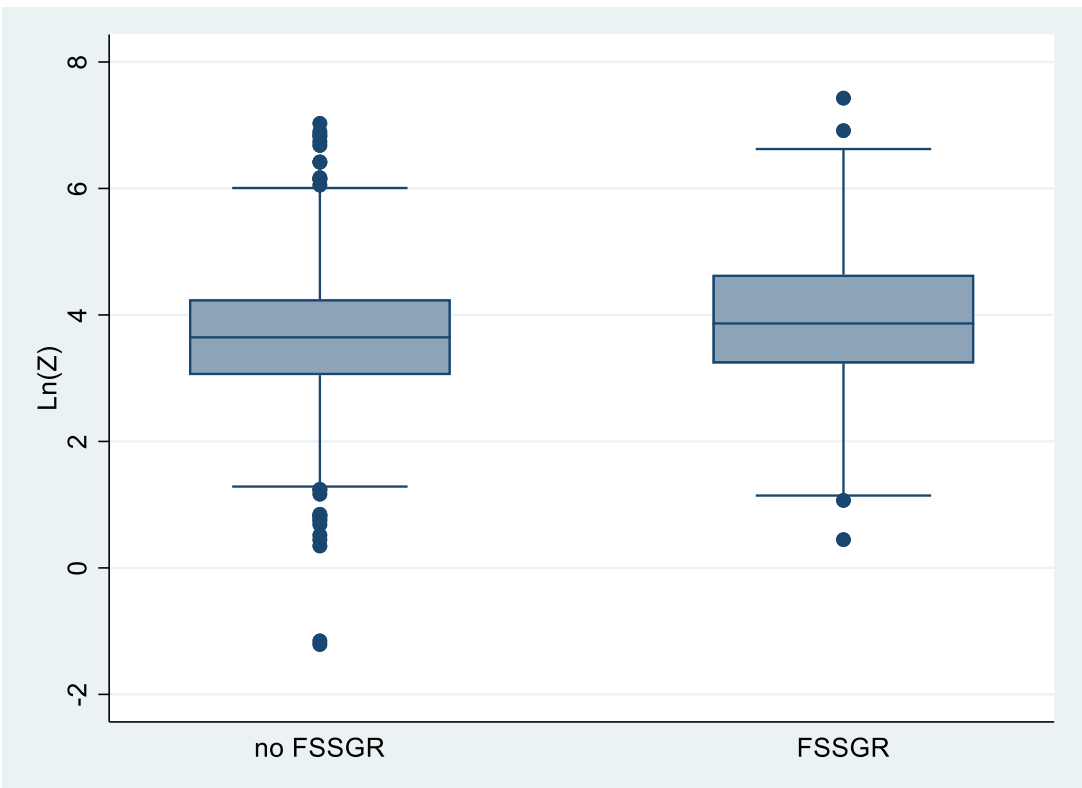

Figure 1. Z-Score of countries with and without FSSRG

As the next step, we conducted a fixed effect panel regression with Z-Score as the dependent variable and FSSRG as well as the control variables Total Asset Growth, Asset to Capital Ratio, Loans Loss Provision / Total Loans, GDP Growth, and Inflation as the independent variables. Before, we conducted a Hausman test. Since the test was significant, we assumed fixed effects. The results are presented in Table 5. The regression function is significant ( $\mathrm{p}$ $<.0001)$. 
Table 5. Panel Regression with fixed effects for the Z-Score as the dependent variable

\begin{tabular}{lll}
\hline Z-Score & Coefficient & Significance \\
\hline FSSRG & 27.74 & 0.021 \\
Total Asset Growth & -72.30 & 0.355 \\
A/E & 717.37 & $<.0001$ \\
LLP/TL & 0.76 & 0.987 \\
dGDP & 2.76 & 0.943 \\
Inflation & -0.41 & 0.716 \\
Constant & -5.94 & 0.61 \\
\hline
\end{tabular}

The result of the analysis suggests a significant positive impact of FSSRG on the Z-Score. The significant control variable is Asset to Capital Ratio. The other control variables did not have a significant effect.

\section{Discussion}

This research demonstrates a relationship between FSSRGs and financial stability for banks in Latin America. This positive relationship implies that banks have higher financial stability when they operate in countries with FSSRG. This result falsifies the null hypothesis that FSSRG does not have an impact on financial stability.

The findings contribute a clearer understanding of sustainable legislation's implications on banks' financial stability. The study results build on existing research regarding the importance of sustainability impacts on the banking sector (Battiston et al., 2017). We conclude that FSSRGs are effective if sustainability issues significantly influence financial stability, as, for instance, other studies suggest (Dafermos et al., 2018; Jiang et al., 2019). Also, this research provides empirical evidence for other policy papers suggesting that FSSRGs help to create a more stable financial sector (Carney, 2017; Zadek \& Robins, 2018). Furthermore, the results are consistent with research that has found lower systemic risk and asset price volatility due to climate risk-related legislation (Battiston et al., 2017). These results build on existing evidence of sustainability regulation in the banking sector, creating stability in the Chinese financial sector (Cui et al., 2018), and contribute by including results from the Latin American banking industry. Hence, it closes the gap of knowledge about the connection between FSSRG and financial stability in general and for the sample of Latin American banks.

Additionally, this research aligns with studies that found positive impacts of evaluating sustainable policies in the financial sector. Some of these studies include the Green Credit Policy in China and in Bangladesh and their relationship with positive financial performance (Cui et al., 2018; Weber \& Chowdury, 2020). FSSRGs have also shown positive impacts on the carbon footprint of a bank's portfolio (Zadek \& Robins, 2015), as well as an increase of corporate social responsibility (CSR) activities and self-regulation in the financial industry (Chih et al., 2010). What the study adds is an analysis outside of Asian countries such as China and Bangladesh.

Furthermore, previous research focused on the adverse effects of climate and social risks on individual and systemic perspectives (Campiglio et al., 2018; Rozenberg et al., 2013), credit risk (Bauer \& Hann, 2010), and financial performance (Dam \& Scholtens, 2015). In contrast, considering that FSSRGs increase sustainable practices in banks, these results demonstrate that the banking sector's sustainable practices promote financial stability. Consequently, 
this research addresses a gap in the academic literature between sustainable finance, financial stability, and macroprudential regulations, as mentioned above. Additionally, most previous empirical research on sustainable finance aimed to study countries like China, Bangladesh, and Nigeria (Jiang et al., 2019; Weber \& Oni, 2015). In contrast, this research mainly researched countries in Latin America, which addresses another gap in the literature that links sustainability and financial studies. Further studies should address other parts of the world to draw more general conclusions about the effect of FSSRG on the financial stability of banks.

Moreover, this study's results represent an opportunity for scholars in economics, financial stability, and sustainability management. The results might be considered when studying the connection between financial stability, systemic risk, and sustainable finance supervisory practices (Carè, 2017). In contrast with popular theories on financial stability that consider the correlation of financial institutions' portfolios as a source of systemic risk (Acharya, 2009), these results show the implications that social and environmental risks have to control systemic risk. Therefore, these results represent an empirical groundwork for developing a theoretical framework that includes the impact of sustainable financial practices and FSSRGs on systemic risk and financial stability, following literature on climate risk and economic stability (Skidmore, 2001).

\section{Conclusion}

Based on the study results, we conclude that FSSRGs have an effect on the financial stability of the banking industry measured by the z-score. Furthermore, we suggest that sustainability, including climate change, is a systemic risk factor for the financial industry.

A limitation of the study is missing data from some banks in the sample. Furthermore, the data has been analyzed through a panel regression that does not present results on the cause and effect of both FSSRGs and Z-score. Finally, the study addresses only one world region. More studies on other regions will provide more insights into the effect of FSSRGs on banking stability in different regions and about differences between regions.

Future research might analyze the change in the banking industry's stability before and after the introduction of FSSRG's to analyze the impact of institutional impact on financial stability and sustainability performance in the banking industry. This approach might address the hypothesis that countries with a more stable financial system are more likely to adapt FSSRGs. 


\section{References}

Acharya, V. V. (2009). A theory of systemic risk and design of prudential bank regulation. Journal of Financial Stability, 5(3), 224-255.

Acharya, V. V., Pedersen, L. H., Philippon, T., \& Richardson, M. (2017). Measuring systemic risk. The Review of Financial Studies, 30(1), 2-47.

Agoraki, M.-E. K., Delis, M. D., \& Pasiouras, F. (2011). Regulations, competition and bank risk-taking in transition countries. Journal of Financial Stability, 7(1), 38-48.

Aizawa, M., \& Chaofei, Y. (2010). Green Credit, Green Stimulus, Green Revolution? China's Mobilization of Banks for Environmental Cleanup. The Journal of Environment \& Development, 19(2), 119-144.

Allen, F., \& Gu, X. (2018). The interplay between regulations and financial stability. Journal of Financial Services Research, 53(2), 233-248.

Allen, R. C. (2011). Global economic history: a very short introduction (Vol. 282). Oxford University Press.

Anderson, R. L. (1954). The problem of autocorrelation in regression analysis. Journal of the American Statistical Association, 49(265), 113-129.

Anginer, D., \& Demirguc-Kunt, A. (2014). Has the global banking system become more fragile over time? Journal of Financial Stability, 13, 202-213.

Barth, J. R., Caprio Jr, G., \& Levine, R. (2004). Bank regulation and supervision: what works best? Journal of Financial Intermediation, 13(2), 205-248.

Battiston, S., Mandel, A., Monasterolo, I., Schuetze, F., \& Visentin, G. (2016). A Climate Stress-Test of the Financial System. In: SSRN.

Battiston, S., Mandel, A., Monasterolo, I., Schuetze, F., \& Visentin, G. (2017). A climate stress-test of the financial system [Article]. Nature Climate Change, 7(4), 283-288. https://doi.org/10.1038/nclimate3255

Bauer, R., \& Hann, D. (2010). Corporate Environmental Management and Credit Risk. SSRN eLibrary. http://ssrn.com/paper $=1660470$

Beck, T., Demirgüç-Kunt, A., \& Levine, R. (2007). Finance, inequality and the poor. Journal of Economic Growth, 12(1), 2749.

Benoit, S., Colliard, J.-E., Hurlin, C., \& Pérignon, C. (2017). Where the risks lie: A survey on systemic risk. Review of Finance, 2l(1), 109-152.

Bermpei, T., Kalyvas, A., \& Nguyen, T. C. (2018). Does institutional quality condition the effect of bank regulations and supervision on bank stability? Evidence from emerging and developing economies. International Review of Financial Analysis, 59, 255-275.

Boyd, J. H., \& Runkle, D. E. (1993). Size and performance of banking firms: Testing the predictions of theory. Journal of monetary economics, 31(1), 47-67.

Campiglio, E., Dafermos, Y., Monnin, P., Ryan-Collins, J., Schotten, G., \& Tanaka, M. (2018). Climate change challenges for central banks and financial regulators. Nature Climate Change, 8(6), 462-468. https://doi.org/10.1038/s41558-018$0175-0$

Carè, R. (2017). Exploring Environmental Disclosure in Banks. Evidence from the Euro Area. ACRN Oxford Journal of Finance and Risk Perspectives, 6(2), 18-40.

Carney, M. (2015). Breaking the Tragedy of the Horizon--climate change and financial stability. Speech given at Lloyd's of London by the Governor of the Bank of England, 29.

Carney, M. (2017). Green finance 'an opportunity' to uphold financial stability. Encvironmental Finance. www.environmentalfinance.com/content/news/greenfinance-an-opportunity-to-uphold-financial-stabilitysays-carney.html

Chan-Fishel, M. (2007). Time to Go Green Environmental Responsibility in the Chinese Banking Sector. In (pp. 107). Amsterdam, The Netherlands: Friends of the Earth and Banktrack.

Chih, H.-L., Chih, H.-H., \& Chen, T.-Y. (2010). On the Determinants of Corporate Social Responsibility: International Evidence on the Financial Industry. Journal of Business Ethics, 93(1), 115-135. https://doi.org/10.1007/s10551-009-0186-X

China Banking Regulatory Commission. (2012). Notice of the China Banking Regulatory Commission CBRC on Issuing the Green Credit Guidelines. China Banking Regulatory Commission.

China Banking Regulatory Commission. (2016, September 2). Green Credit in helping the adjustment of economic structure and the upgrade in industry transformation [transl.]

Čihák, M., \& Hesse, H. (2010). Islamic banks and financial stability: An empirical analysis. Journal of Financial Services Research, 38(2-3), 95-113.

Cui, Y., Geobey, S., Weber, O., \& Lin, H. (2018). The Impact of Green Lending on Credit Risk in China. Sustainability, 10(6), 2008. https://doi.org/doi.org/10.3390/su10062008

Dafermos, Y., Nikolaidi, M., \& Galanis, G. (2018). Climate Change, Financial Stability and Monetary Policy. Ecological Economics, 152, 219-234. https://doi.org/https://doi.org/10.1016/j.ecolecon.2018.05.011

Dam, L., \& Scholtens, B. (2015). Towards a Theory of Responsible Investing: On the Economic Foundations of Corporate Social Responsibility. RESOURCE AND ENERGY ECONOMICS, 4l(August), $103-121$. https://doi.org/http://dx.doi.org/10.1016/j.reseneeco.2015.04.008 
Delis, M. D., Tran, K. C., \& Tsionas, E. G. (2012). Quantifying and explaining parameter heterogeneity in the capital regulationbank risk nexus. Journal of Financial Stability, 8(2), 57-68.

Demirguc-Kunt, A., Detragiache, E., \& Tressel, T. (2006). Banking on the principles: Compliance with Basel Core Principles and bank soundness. The World Bank.

Demirguc-Kunt, A., \& Huizinga, H. (2009). Bank activity and funding strategies: The impact on risk and returns. The World Bank.

Dietz, S., Bowen, A., Dixon, C., \& Gradwell, P. (2016). Climate value at risk' of global financial assets. Nature Climate Change, 6, 676. https://doi.org/10.1038/nclimate2972

Dietz, T., Ostrom, E., \& Stern, P. C. (2003). The struggle to govern the commons. Science, 302(5652), $1907-1912$.

Dorfleitner, G., \& Utz, S. (2012). Safety first portfolio choice based on financial and sustainability returns. European Journal of Operational Research, 221(1), 155-164. https://doi.org/10.1016/j.ejor.2012.02.034

ElAlfy, A., Palaschuk, N., El-Bassiouny, D., Wilson, J., \& Weber, O. (2020). Scoping the Evolution of Corporate Social Responsibility (CSR) Research in the Sustainable Development Goals (SDGs) Era. Sustainability, 12, 5544.

Farhi, E., \& Tirole, J. (2012). Collective moral hazard, maturity mismatch, and systemic bailouts. American Economic Review, 102(1), 60-93.

Hausman, J. A. (1978). Specification tests in econometrics. Econometrica: Journal of the Econometric Society, $1251-1271$.

Hayne, M., Ralite, S., Thomä, J., \& Koopman, D. Factoring transition risks into regulatory stress-tests: The case for a standardized framework for climate stress testing and measuring impact tolerance to abrupt late and sudden economic decarbonization.

Jackson, E. T. (2013). Interrogating the theory of change: evaluating impact investing where it matters most. Journal of Sustainable Finance \& Investment, 1-16. https://doi.org/10.1080/20430795.2013.776257

Jensen, M. C., \& Meckling, W. H. (1976). Theory of the firm: Managerial behavior, agency costs and ownership structure. Journal of Financial Economics, 3(4), 305-360.

Jiang, Y., Li, C., Zhang, J., \& Zhou, X. (2019). Financial stability and sustainability under the coordination of monetary policy and macroprudential policy: New evidence from China. Sustainability, 11(6), 1616.

Klomp, J. (2014). Financial fragility and natural disasters: An empirical analysis. Journal of Financial Stability, 13, $180-192$.

Laeven, L., \& Levine, R. (2009). Bank governance, regulation and risk taking. Journal of Financial Economics, 93(2), 259-275.

Monasterolo, I., Battiston, S., Janetos, A. C., \& Zheng, Z. (2017). Vulnerable yet relevant: the two dimensions of climate-related financial disclosure [journal article]. Climatic Change, 145(3), 495-507. https://doi.org/10.1007/s10584-017-2095-9

Monasterolo, I., \& Raberto, M. (2018). The EIRIN flow-of-funds behavioural model of green fiscal policies and green sovereign bonds. Ecological Economics, 144, 228-243.

Nofsinger, J., \& Varma, A. (2014). Socially responsible funds and market crises. J Bank Finan, 48, 180-193.

Oyegunle, A., \& Weber, O. (2015). Development of Sustainability and Green Banking Regulations - Existing Codes and Practices. In (pp. 24). Waterloo, ON: Center for International Governance Innovation (CIGI).

Pellegrino, C., \& Lodhia, S. (2012). Climate change accounting and the Australian mining industry: exploring the links between corporate disclosure and the generation of legitimacy. Journal of Cleaner Production, 36(0), 68-82. https://doi.org/http://dx.doi.org/10.1016/j.jclepro.2012.02.022

Petersen, M. A. (2009). Estimating Standard Errors in Finance Panel Data Sets: Comparing Approaches. Review of Financial Studies, 22(1), 435-480. https://doi.org/10.1093/rfs/hhn053

Rozenberg, J., Hallegatte, S., Perrissin-Fabert, B., \& Hourcade, J.-C. (2013). Funding low-carbon investments in the absence of a carbon tax. Climate Policy, 13(1), 134-141.

Saravade, V., \& Weber, O. (2020). An Institutional Pressure and Adaptive Capacity Framework for Green Bonds: Insights from India's Emerging Green Bond Market. World, 1(3), 239-263. https://www.mdpi.com/2673-4060/1/3/18

Sarro, D. (2012). Do Lenders Make Effective Regulators? An assessment of the Equator Principles on project finance. German Law Journal, 13(12), 1522-1555.

Schinasi, G. J. (2004). Defining financial stability (IMF Working Paper, Issue. https://papers.ssrn.com/Sol3/papers.cfm?abstract id=879012

Scholtens, B., Cerin, P., \& Hassel, L. (2008). Sustainable development and socially responsible finance and investing. Sustainable Development, 16(3), 137-140.

Scholtens, B., \& Dam, L. (2007). Banking on the Equator. Are Banks that Adopted the Equator Principles Different from NonAdopters? World Development, 35(8), 1307-1328. https://doi.org/http://dx.doi.org/10.1016/j.worlddev.2006.10.013

Scott, M., Van Huizen, J., \& Jung, C. (2017). The bank's response to climate change. Bank of England Quarterly Bulletin, Q2.

Shehzad, C. T., \& De Haan, J. (2015). Supervisory powers and bank risk taking. Journal of International Financial Markets, Institutions and Money, 39, 15-24.

Skidmore, M. (2001). Risk, natural disasters, and household savings in a life cycle model. Japan and the World Economy, 13(1), $15-34$.

Stiglitz, J. E., \& Weiss, A. (1988). Banks as social accountants and screening devices for the allocation of credit [Working Paper](2710). (NBER Working Paper Series, Issue. N. B. o. E. Research.

Tabak, B. M., Fazio, D. M., \& Cajueiro, D. O. (2013). Systemically important banks and financial stability: The case of Latin America. J Bank Finan, 37(10), 3855-3866. 
Wang, Y., \& Zhi, Q. (2016). The role of green finance in environmental protection: Two aspects of market mechanism and policies. Energy Procedia, 104, 311-316.

Weber, O. (2005). Sustainability Benchmarking of European Banks and Financial Service Organizations. Corporate Social Responsibility and Environmental Management, 12, 73-87.

Weber, O. (2017). Corporate sustainability and financial performance of Chinese banks. Sustainability Accounting, Management and Policy Journal, 8(3), 358-385. https://doi.org/10.1108/SAMPJ-09-2016-0066

Weber, O., \& Chowdury, R. K. (2020). Corporate Sustainability in Bangladeshi Banks: Proactive or Reactive Ethical Behavior? Sustainability, 12(19), 7999. https://www.mdpi.com/2071-1050/12/19/7999

Weber, O., \& Feltmate, B. (2016). Sustainable Banking: Managing the Social and Environmental Impact of Financial Institutions. University of Toronto Press. https://books.google.ca/books?id=mrNCjgEACAAJ

Weber, O., \& Oni, O. (2015). The Impact of Financial Sector Sustainability Regulations on Banks. In (pp. 24). Waterloo, ON: CIGI.

Weber, O., Scholz, R. W., \& Michalik, G. (2010). Incorporating sustainability criteria into credit risk management. Business Strategy and the Environment, 19(1), 39-50. https://doi.org/10.1002/bse.636

World Bank. (2018). Sustainable Banking Network (SBN) - Global progress report, 2018. International Finance Corporation, IFC.

Zadek, S., \& Robins, N. (2015). Aligning the financial system with sustainable development. In (pp. 34). Geneva, Switzerland: UNEP.

Zadek, S., \& Robins, N. (2018). Making Waves - Aligning the financial system with sustainable development. United Nations Environment Programme. http://unepinquiry.org/wp-content/uploads/2018/04/Making_Waves.pdf

Zhang, B., Yang, Y., \& Bi, J. (2011). Tracking the implementation of green credit policy in China: Top-down perspective and bottom-up reform. Journal of Environmental Management, $1321-1327$. https://doi.org/10.1016/j.jenvman.2010.12.019

(C) 2021 by the authors. Licensee ACRN Publishing, Austria, Editor in Chief Prof. Dr. Othmar M. Lehner. This article is an open access article distributed under the terms and conditions of the Creative Commons Attribution (CC BY SA) license (https://creativecommons.org/licenses/by-sa/4.0/) 